\title{
PROPOSTA DE NOVA METODOLOGIA DE APOIO PARA INDICAÇÃO RACIONAL DE PROFILAXIA ANTIRRÁBICA HUMANA PÓS-EXPOSIÇÃO
}

\author{
Danila Fernanda Rodrigues Frias ${ }^{1}$ \\ Adolorata Aparecida Bianco Carvalho ${ }^{2}$ \\ Juliana Olivência Ramalho Nunes²
}

FRIAS, D. F. R.; CARVALHO, A. A. B.; NUNES, J. O. R. Proposta de nova metodologia de apoio para indicação racional de profilaxia antirrábica humana pós-exposição. Arq. Cienc. Saúde UNIPAR, Umuarama, v. 20, n. 1, p, 9-18, jan./abr. 2016.

\begin{abstract}
RESUMO: A avaliação dos casos de agressão por animais, sem critérios bem definidos, pode levar à indicação equivocada de tratamento antirrábico humano pós-exposição. O número desses tratamentos, em muitos municípios em todo o Brasil, tem preocupado as autoridades sanitárias. Assim, o presente trabalho objetivou avaliar os registros e a conduta da profilaxia antirrábica humana no Município de Jaboticabal, no período de 2007 a 2010, e propor uma nova metodologia de ação. Foi elaborada uma nova ficha de atendimento antirrábico humano, a ficha referência de atendimento a agressão animal e a ficha de visita zoossanitária, todas com seus respectivos manuais de instrução para preenchimento. Além disso, realizou-se a capacitação dos responsáveis pela sua aplicação e as visitas zoossanitárias. Foram avaliadas as informações das fichas de atendimento e dos resultados de visitas domiciliares e observação dos animais agressores; os dados foram tabulados em Excel e analisados com softwares EpiInfo e Action. Também calculou-se o custo direto das vacinas antirrábicas humanas aplicadas. Em 1.366 fichas analisadas, computou-se um agravo para cada 212 habitantes; das pessoas agredidas, 74,3\% receberam tratamento pós-exposição, num total de 1.251 doses de vacina. A análise detalhada dos dados, aliada ao fato de Jaboticabal ser considerada região controlada para a raiva, permite questionar que 894 pessoas podem ter recebido vacina sem necessidade, totalizando 1.094 doses a um custo aproximado de 20 mil reais. Nas visitas zoossanitárias constatou-se que, dentre os animais agressores, 78,1\% eram domiciliados; $84,4 \%$ estavam sadios nos dias 0 e 10; 55\% dos ataques foram provocados, e 73\% das agressões ocorreram nas próprias residências. Assim, maior atenção deve ser dispensada ao atendimento a agravos por animais, com adequações na ficha de registro, aplicação das fichas referência de atendimento a agressão animal e de visita zoossanitária. É essencial a interação dos serviços médicos e médicos veterinários, além da intensificação de programas educativos sobre comportamento animal, cuidados e posse responsável. Isso dará subsídios e segurança ao médico responsável no momento de indicar ou não o tratamento antirrábico humano pós-exposição.
\end{abstract}

PALAVRAS-CHAVE: Agravos por animais. Cães. Gatos. Raiva. Zoonoses.

\section{PROPOSAL OF NEW SUPPORT METHODOLOGY FOR RATIONAL INDICATION OF POST-EXPOSURE HUMAN ANTI- RABIES PROPHYLAXIS}

\begin{abstract}
A poor assessment of cases of animal attacks on humans may lead to inadequate human anti-rabies prophylaxis. The high number of post-exposure prophylaxis (PEP) treatments in many Brazilian cities has become a concern for Public Health authorities. The present study aimed to assess the records and the conduct of human PEP in the municipality of Jaboticabal, in the period 2007-2010, and to propose a new methodology. Versions for the following forms, together with instructions for filling them out, are proposed: human rabies medical attention form, animal attack notification form, and an animal-sanitary visit form. The personnel in charge of the health sector were trained for filling out these forms and conducting visits. The analysis of patient's records and the results of home visitation and animal observation data were evaluated. Data were organized in Excel spreadsheet and analyzed using EpiInfo and Action software. The direct cost of human vaccination was also calculated. From the 1,366 analyzed records, there was one animal attack per 212 inhabitants. Among the affected people, $74.3 \%$ received PEP, resulting in a total of 1,251 vaccine shots. The fact that Jaboticabal is located in a region that has a controlled status for rabies, together with the data analysis, allowed hypothesizing that 894 persons may have received unnecessary rabies shots, which resulted in a total of 1,094 shots at a cost of approximately 20 thousand Brazilian reais. During the animal-sanitary visits, it could be observed that among the aggressors, $78.1 \%$ were domiciled animals; $84.4 \%$ remained healthy between observation days 0 to 10 ; $55 \%$ of the attacks were provoked and $73 \%$ of the events happened inside the domicile. It can be concluded that greater importance should be given to animal attack cases. The patient's records, animal attack notification form and animal-sanitary visit forms should be reviewed and duly amended. The integration of medical and veterinary services is essential, as well as the intensification of educational programs on animal behavior, care and responsible ownership. These actions will provide greater support and safety to the physician in charge upon deciding whether to provide PEP treatment or not.
\end{abstract}

KEYWORDS: Animal attack. Cats. Dogs. Rabies. Zoonosis.

\section{Introdução}

A raiva é considerada uma das mais importantes zoonoses conhecidas e se mantém como um sério problema de saúde pública em todo o mundo, devido ao grande número de pessoas ainda expostas ao risco de contrair a enfermidade e ao alto custo do tratamento humano pós-exposição e de outras ações de prevenção e controle, além do fato de ser uma virose com alta taxa de mortalidade (BELOTTO et al., 2005).
A principal via de eliminação do vírus da raiva é a saliva, e a mordedura de animais infectados é a forma mais comum de transmissão da doença. Como o cão possui maior proximidade e interação com seres humanos, favorecendo situações de agravos, torna-se a principal espécie transmissora (SCHNEIDER et al., 2007).

Em casos de agressão causada por mamíferos transmissores de raiva, a vítima deve procurar auxílio médico. Os procedimentos técnicos vão desde a análise do histórico da

DOI: https://doi.org/10.25110/arqsaude.v20i1.2016.4955

${ }^{1}$ Professora titular, Universidade Camilo Castelo Branco, Campus de Fernandópolis, São Paulo. Endereço para correspondência: Danila Fernanda Rodrigues Frias - Estrada Projetada F-1, s/n, Fazenda Santa Rita, Fernandópolis, São Paulo, CEP 15600-000. E-mail: danilafrias@yahoo.com.br.

${ }^{2}$ Departamento de Medicina Veterinária Preventiva e Reprodução Animal. Faculdade de Medicina Veterinária. Universidade Estadual Paulista “Julio de Mesquita Filho". Jaboticabal, São Paulo. adbianco@fcav.unesp.br; jubiju@terra.com.br. 
agressão e da condição epidemiológica da doença, até a instituição de tratamento pós-exposição com utilização de vacina ou sorovacinação (BRASIL, 2000; BRASIL, 2014).

No Brasil, embora a raiva urbana esteja controlada na maioria dos estados e a ocorrência da doença em humanos tenha diminuído significativamente, é grande o número de tratamentos pós-exposição efetuados em decorrência do envolvimento de pessoas em acidentes com cães ou gatos (BELOTTO et al., 2005; FRIAS, 2008; FRIAS; LAGES; CARVALHO, 2011).

Os acidentes, principalmente as mordeduras, acarretam grandes preocupações, não apenas pela possibilidade de transmissão da raiva, pelos danos físicos e emocionais, mas também pelas despesas geradas em decorrência dos cuidados em medicina assistencial (BRASIL, 2003). Essa preocupação com o aspecto econômico da raiva já vem sendo manifestada há algum tempo pelas autoridades do próprio Ministério da Saúde, uma vez que são extremamente elevados os custos com tratamentos pós-exposição (OLIVEIRA; SILVA; GOMES, 2010).

Existem relatos de falhas na aplicação das normas técnicas de profilaxia antirrábica humana, em muitos municípios brasileiros e também em outros países. Essas falhas levam à instituição de tratamento pós-exposição de forma inadequada, muitas vezes desnecessária, gerando grandes demandas aos cofres públicos, principalmente com o uso dos imunobiológicos (BELOTTO et al., 2005; FRIAS, 2008; FRIAS; LAGES; CARVALHO, 2011).

No Município de Jaboticabal/SP, em estudo realizado entre os anos de 2000 e 2006, constatou-se que $81,6 \%$ das pessoas agredidas por animais receberam pelo menos uma dose de vacina antirrábica, e que a conduta seguia, basicamente, a recomendação relativa à gravidade da lesão (FRIAS, 2008; FRIAS; LAGES; CARVALHO, 2011). De acordo com as Normas Técnicas de Profilaxia Antirrábica Humana, mesmo em casos de exposição de natureza grave, deve-se avaliar a condição epidemiológica da doença na região, a circunstância da agressão (se provocada ou acidental), e a possibilidade de observação de cão ou gato agressor (BRASIL, 2000; BRASIL, 2014). Ademais, existem falhas na própria ficha oficial de notificação de agravos, com ausência de campos de informação importantes para subsidiar a análise epidemiológica do caso (FRIAS, 2008; FRIAS; LAGES; CARVALHO, 2011).

O presente estudo estendeu até 2010 a análise dos registros de atendimento antirrábico e da conduta de tratamento humano pós-exposição em acidentes envolvendo cães e gatos no Município de Jaboticabal/SP, comparando os resultados com os do período anterior. Além disso, propôs estabelecer uma nova metodologia de ação investigativa do agravo e fornecer subsídios ao Serviço de Vigilância Epidemiológica para indicação segura e correta desse tratamento.

\section{Metodologia}

\section{Diagnóstico de situação dos atendimentos antirrábicos humanos}

Foi realizado um levantamento dos dados registrados nas fichas de investigação de atendimento antirrábico humano no Município de Jaboticabal/SP, no período de $1^{\circ}$ de janeiro de 2007 a 31 de dezembro de 2010.

\section{Obtenção e digitalização dos dados}

A pesquisa dos dados foi efetuada na Secretaria de Vigilância Epidemiológica (SVE) do Município de Jaboticabal, com autorização oficial do secretário de saúde.

As fichas de investigação de atendimento antirrábico humano estavam arquivadas na pasta (prontuário) de cada paciente. Para facilitar seu resgate, a SVE disponibilizou uma lista do Sistema de Informações de Agravos de Notificação (SINAN), contendo os nomes das pessoas envolvidas em acidentes com animais e que procuraram atendimento durante o período estudado. A partir dessa lista, efetuou-se uma pesquisa no computador do Centro de Saúde que gerou os números das pastas prontuário. As fichas de investigação de atendimento antirrábico eram extraídas das pastas de cada um desses pacientes e, após imediata digitalização dos dados, tudo era devolvido ao arquivo.

\section{Formação do banco de dados}

Foram analisadas 1.366 fichas relativas ao período de $1^{\circ}$ de janeiro de 2007 a 31 de dezembro de 2010. A identificação dos pacientes foi omitida por questões éticas.

A ficha é composta por 65 campos distribuídos em seis sessões diferentes. As sessões compreendem dados gerais do paciente, notificação individual, dados da residência, antecedentes epidemiológicos, tratamento atual do caso e nome do investigador. Para a presente pesquisa, foram utilizados os seguintes campos, de quatro das sessões: Ano e mês da ocorrência do agravo; Idade e sexo do agredido; Tipo de exposição; Região anatômica atingida; Características do ferimento quanto à extensão e ao número de lesões, e quanto à profundidade; Tratamento antecedente e quando este teve início; Espécie do animal agressor; Condição do animal no ato do acidente e durante o período de observação; Conduta relacionada ao agravo: número de doses indicadas ao paciente e observação do animal, ou apenas observação do animal; Interrupção do tratamento e motivo da interrupção e Indicação de soro antirrábico.

\section{Tabulação e análise dos dados}

Após obtenção e digitalização, os dados foram tabulados em planilhas do software Microsoft Office Excel 2010 e analisados por meio do software EpiInfo versão 3.3.2. Os resultados foram dispostos em tabelas e gráficos.

A análise estatística foi realizada utilizando-se o Action 2.1, suplemento do programa Excell.

\section{Estratégia de ação para orientar a indicação de trata- mento antirrábico humano pós-exposição}

Com o propósito de buscar subsídios para orientar tratamentos antirrábicos humanos pós-exposição e demonstrar a indicação possivelmente equivocada no Município de Jaboticabal/SP, foram elaborados e aplicados novos modelos de fichas e estabelecidas as visitas zoossanitárias com observação dos animais agressores.

Estabeleceu-se para o período de 23 de março a 21 de junho de 2011 a realização de um plano piloto para testar e analisar o uso das fichas propostas.

\section{Proposta de novo modelo de ficha de atendimento antir- rábico humano}

Foi elaborado um novo modelo de ficha de aten- 
dimento antirrábico humano, com modificações pertinentes que permitirão melhor entendimento e facilidade para preenchimento. Os principais campos adicionados foram: condição vacinal do animal agressor; se a agressão foi provocada; local de ocorrência da agressão e tratamento efetuado.

Para o correto preenchimento da ficha de atendimento antirrábico humano foi criado um Manual de Instruções contendo a descrição de cada campo e orientações. Realizou-se a capacitação, por meio de palestras, das pessoas responsáveis pelo preenchimento da referida ficha, incluindo enfermeiros e atendentes.

A ficha de atendimento que vinha sendo utilizada foi mantida pelo fato de ser um documento oficial do Ministério da Saúde, cujos dados devem ser anexados no SINAN. Assim, ela não pôde ser substituída pelo modelo proposto, durante o período de estudo no Município de Jaboticabal e, por isso, criou-se um anexo contendo os quatro campos inseridos, o qual foi grampeado à ficha padrão em uso.

A referida ficha com o anexo foi preenchida pela enfermeira e pelo médico responsável, no ato do atendimento ao paciente junto ao Serviço de Vigilância Epidemiológica, no Centro Integrado de Atendimento à Família (CIAF) 6.

\section{Modelo de ficha referência de atendimento a agressão animal}

No Município de Jaboticabal/SP, a procura por atendimento médico após uma agressão por animal pode ser feita em qualquer um dos sete CIAFs ou no Pronto Atendimento Municipal. Porém, a notificação, com o preenchimento da ficha de atendimento antirrábico humano, e o acompanhamento do caso, ocorrem apenas no CIAF6. Por este motivo, quando as vítimas de agravos envolvendo animais são atendidas em outro local, lá são prestados os primeiros socorros, é preenchida a Ficha de Referência de Pacientes e feito o encaminhamento ao CIAF6.

Como a Ficha de Referência de Pacientes não é exclusiva para atendimento a pessoas agredidas por animais, faltam dados que são essenciais para a pesquisa do caso, especialmente quando não se consegue localizar a vítima.

Por este motivo, constatou-se a necessidade da formulação de ficha específica para referência de agressão. Esta foi elaborada e contempla campos importantes para o estudo epidemiológico do caso, além de facilitar o trabalho dos responsáveis pelo preenchimento. Vale ressaltar que a nova ficha permite detectar as subnotificações ao CIAF6. A capacitação das enfermeiras responsáveis por cada CIAF e pelo Pronto Atendimento para preenchimento desta nova ficha foi realizada por meio de palestra explicativa. Essas profissionais deveriam compor o grupo de multiplicadores, os quais seriam os responsáveis por passar as orientações a todos os subordinados.

A ficha foi distribuída em todos os CIAFs e no Pronto Atendimento do Município. O Serviço de vigilância epidemiológica do Município ficou responsável pela reposição, quando necessário.

\section{Modelo de ficha de visita zoossanitária}

Para o acompanhamento do animal agressor no período de dez dias, foi desenvolvida uma ficha de visita zoossanitária que contempla dados do animal agressor e seu estado sanitário, e a forma como aconteceu a agressão.
Para o correto preenchimento da ficha foi criado um manual de instruções contendo a descrição de cada campo e as orientações.

Por meio de palestra explicativa, foi realizada a capacitação dos atendentes do CIAF6, que ficaram responsáveis pelo preenchimento do cabeçalho da ficha, e do médico veterinário responsável pela aplicação das mesmas.

\section{Análise da indicação de tratamento antirrábico humano pós-exposição}

A conduta do médico responsável pela indicação do tratamento humano pós-exposição ocorreu normalmente, sem que o mesmo tomasse conhecimento dos resultados da ficha zoossanitária, com o propósito de consolidar os resultados da primeira fase deste estudo. Essa análise foi realizada com base nas Normas Técnicas de Atendimento Antirrábico Humano e nos resultados da aplicação das fichas, as quais se complementam.

\section{Resultados}

\section{Diagnóstico de situação dos atendimentos antirrábicos} humanos

1.1. Análise dos dados relativos a notificação de agravos por animais

Entre $1^{\circ}$ de janeiro de 2007 e 31 de dezembro de 2010 foram notificados 1.366 casos, ou seja, 1.366 pessoas procuraram atendimento médico devido a qualquer tipo de agravo por animais.

A média da população de Jaboticabal nesse período era 72.453 habitantes (IBGE, 2011), portanto a taxa anual de notificação de agravos envolvendo animais foi 1:212 (uma pessoa agredida para cada 212 habitantes).

A condição da pessoa envolvida no acidente já ter recebido profilaxia antirrábica anteriormente foi observada em $18,7 \%$ das ocasiões. Também foi observado que em 7,2\% das fichas o campo não foi preenchido.

Durante os anos de estudo, 85,5\% dos agravos foram provocados por cães e $8,7 \%$, por gatos; portanto, o cão foi o responsável pela maioria dos acidentes, em todos os anos.

No presente estudo, em $89 \%$ dos casos o animal foi declarado sadio no momento do agravo e $84,6 \%$ mantiveram-se sadios durante o período de observação. Vale ressaltar que a "observação" era realizada pelo próprio dono e verificada, via telefone, pela atendente responsável no Serviço de Vigilância, que fazia as anotações nas fichas. Fato importante, também, é que em algumas fichas esse dado não era preenchido, o que impossibilitou conhecer o número real de animais que permaneceram sadios, certamente ainda maior que os $84,6 \%$ acima mencionados

No período estudado, das 1.336 pessoas envolvidas em acidentes com animais, 1.015 (74,3\%) foram submetidas ao tratamento com uso de vacina antirrábica. O número de casos conduzidos apenas com a observação do animal, ou seja, sem instituição de vacina, foi $351(25,7 \%)$.

A porcentagem de indicações de tratamento antirrábico pós-exposição em Jaboticabal foi de 74,3\% das pessoas agredidas.

Pode-se constatar, no presente estudo, que a con- 
dição de animal sadio, tanto no momento do atendimento do caso, como no período de observação, foi declarada pelo próprio paciente ou acompanhante, quando as normas preconizam que um profissional de saúde deve acompanhar esta observação.

Para analisar e questionar a conduta de profilaxia pós-exposição em humanos adotada em Jaboticabal, no período de estudo, foram tomados apenas os dados das fichas de atendimento antirrábico relativas a agravos causados por cães e gatos. Considerando o município estudado como área controlada para a raiva, e que 1.155 agravos foram causados por cães e gatos domiciliados e clinicamente sadios no momento do acidente e durante todo o período de observação, pode-se inferir que todos os 1.155 pacientes poderiam ter sido dispensados do tratamento com vacina. Porém, apenas 131 o foram e, para outros 130, foi indicado apenas a observação do animal; os demais 894 receberam vacina. Compreende-se, então, que do total de 1.366 acidentes ocorridos no período de estudo, $894(65,4 \%)$ podem ter sido conduzidos ao tratamento de forma equivocada, ou seja, não seria necessário a indicação de vacinas.

Notou-se, também, que a indicação de tratamento pós-exposição, na maioria dos casos, foi feita com base apenas na caracterização do agravo, ou seja, local do ferimento, tipo da lesão e gravidade. Isso se justifica pelo sistema adotado, o qual não interrelaciona os serviços médicos e médicos veterinários, restando aos médicos apenas a alternativa de indicar ou dispensar tratamento e analisar os riscos de infecção nas evidências de lesões produzidas pelos animais.

De um modo geral, não foi considerada a condição epidemiológica da doença no Município, nem a condição do animal no momento da agressão.

\section{Estratégia de ação para orientar a indicação de trata- mento antirrábico humano pós-exposição}

Análise do anexo da ficha de atendimento antirrábico humano

Os resultados encontrados após aplicação do anexo da ficha de atendimento antirrábico durante 90 dias de aplicação estão descritos na Tabela 1 .

Tabela 1: Resultado da aplicação do anexo da ficha de atendimento antirrábico humano durante o período de 23 de março a 21 de junho de 2011. Jaboticabal, SP, Brasil

\begin{tabular}{l|c|c}
\hline & $\begin{array}{c}\text { Número de } \\
\text { Agravos }\end{array}$ & Percentual \\
\hline
\end{tabular}

\section{Animal vacinado contra raiva?}

\begin{tabular}{l|c|c}
\hline Sim & 34 & 47,9 \\
\hline Não & 9 & 12,7 \\
\hline Ignorado & 15 & 21,1 \\
\hline Ficha Incompleta & 13 & 18,3 \\
\hline
\end{tabular}

O ataque foi provocado?

\begin{tabular}{l|l|l}
\hline Sim & 39 & 55,0 \\
\hline Não & 16 & 22,5 \\
\hline Ficha Incompleta & 16 & 22,5 \\
\hline
\end{tabular}

\section{Local da agressão}

\begin{tabular}{l|c|c}
\hline Residência & 52 & 73,3 \\
\hline
\end{tabular}

\begin{tabular}{l|c|c}
\hline Via pública & 15 & 21,1 \\
\hline Zona rural & 0 & 0 \\
\hline Outro & 0 & 0 \\
\hline Ficha Incompleta & 4 & 5,6 \\
\hline
\end{tabular}

Tratamento efetuado

\begin{tabular}{l|c|c}
\hline Pré-exposição & 0 & 0 \\
\hline Dispensa tratamento & 0 & 0 \\
\hline Observação do animal & 12 & 16,9 \\
\hline Observação+vacina & 35 & 49,3 \\
\hline Vacina & 5 & 7,0 \\
\hline Vacina+soro & 4 & 5,7 \\
\hline Observação+vacina+soro & 2 & 2,8 \\
\hline Vacina+dispensa tratamento & 0 & 0 \\
\hline Re-exposição & 3 & 4,3 \\
\hline Ficha Incompleta & 10 & 14,0 \\
\hline
\end{tabular}

Quando questionadas sobre a situação vacinal do animal agressor, 47,9\% das vítimas declararam animal vacinado contra a raiva. Com relação à circunstância do ataque, $55 \%$ das vítimas declararam o ataque como sendo provocado. Quanto à localização geográfica onde ocorreu a agressão, residência foi declarada o maior número de vezes $(73,3 \%)$.

No que se refere à conduta médica adotada, o mais comum foi a indicação de aplicação de vacina antirrábica associada a observação do animal. Em 16,9\% dos casos houve indicação apenas de observação do animal agressor. A indicação de vacina antirrábica humana ocorreu em $69,1 \%$ dos casos.

A falta de preenchimento de campos do anexo da ficha, como no caso da circunstância da agressão, ausente em $22,5 \%$ dos anexos, prejudicou o resultado da pesquisa.

\section{Análise da ficha referência de atendimento a agressão} animal

Durante os 90 dias de aplicação do plano piloto ocorreram 71 notificações de agressões por animais, ou seja, 71 pessoas foram agredidas, procuraram auxílio médico e prosseguiram o tratamento indicado. Quando as vítimas não dão prosseguimento às recomendações indicadas, o caso não é adicionado ao banco de dados do SINAN, caracterizando-se, assim, uma subnotificação.

No período do plano piloto, pela ficha referência de agressão animal, foram detectadas 15 subnotificações, ou seja, 15 pessoas procuraram auxílio médico por causa da agressão no Pronto Atendimento, mas deram prosseguimento às recomendações, ou seja, não procuraram o CIAF6. Dentre as 15 vítimas, oito receberam a primeira dose de vacina antirrábica no momento do atendimento.

Em posse da ficha referência de agressão animal, foram visitadas 11 das 15 pessoas agredidas (correspondentes aos casos de subnotificação); as outras quatro não foram localizadas por motivo de mudança de endereço e endereço e/ou telefone inexistentes. A descrição das agressões e a conduta terapêutica adotada em cada um dos 11 casos encontram-se na Tabela 2. 
Tabela 2: Descrição do resultado da aplicação da ficha referência de atendimento a agressão animal, relativo aos 11 casos subnotificados de agressão por animais, durante o período de 23 de março a 21 de junho de 2011. Jaboticabal, SP, Brasil

\begin{tabular}{l|c|c|c|l}
\hline \multicolumn{1}{c|}{ Motivo da agressão } & $\begin{array}{c}\text { Espécie } \\
\text { agressora }\end{array}$ & $\begin{array}{c}\text { Tipo de } \\
\text { exposição }\end{array}$ & Localização & \multicolumn{1}{c|}{$\begin{array}{c}\text { Conduta } \\
\text { Terapêutica }\end{array}$} \\
\hline 1 - Separação de briga entre animais & Canina & Mordedura & Membros superiores & $\begin{array}{l}\text { Observação do animal; } \\
\text { orientações }\end{array}$ \\
\hline 2 - Separação de briga entre animais & Canina & Mordedura & $\begin{array}{l}\text { Vacina antirrábica; antibiótico; } \\
\text { limpeza local; completar o } \\
\text { esquema vacinal }\end{array}$ \\
\hline 3 - Separação de briga entre animais & Canina & Mordedura & Membros superiores & Orientações \\
\hline 4 - Entrada em quintal de amigo & Canina & Mordedura & Membros inferiores & $\begin{array}{l}\text { Orientações para paciente } \\
\text { gestante; observação do animal }\end{array}$ \\
\hline 5 - Entrada em quintal de amigo & Canina & Mordedura & Membros inferiores & $\begin{array}{l}\text { Vacina antitetânica; vacina } \\
\text { antirrábica; orientações }\end{array}$ \\
\hline \begin{tabular}{l}
6 - Entrada em quintal de amigo \\
\hline - Agressão ao animal
\end{tabular} & Canina & Mordedura & Membros inferiores & Vacina antirrábica; Curativo \\
\hline 8 - Agressão ao animal & Canina & Mordedura & Membros superiores & Orientações \\
\hline $\begin{array}{l}9 \text { - Animal com estresse provocado } \\
- \text { dor }\end{array}$ & Canina & Mordedura & Cabeça/pescoço & $\begin{array}{l}\text { Vacina antirrábica; limpeza } \\
\text { local }\end{array}$ \\
\hline $\begin{array}{l}10 \text { - Animal com estresse provocado } \\
- \text { Pet Shop }\end{array}$ & Canina & Mordedura & Cabeça/pescoço & $\begin{array}{l}\text { Vacina antirrábica; observação } \\
\text { do animal; curativo }\end{array}$ \\
\hline 11 - Ataque sem justificativa & Canina & Mordedura & Cabeça/pescoço & Antibiótico \\
\hline
\end{tabular}

A taxa de subnotificações de agressão animal no Município de Jaboticabal, medida no período de 90 dias, foi de $21,1 \%$.

\section{Análise da ficha de visita zoossanitária}

$\mathrm{Na}$ análise da ficha de visita zoossanitária foram realizadas 64 visitas domiciliares e observação dos animais agressores, dentre as 71 notificações ocorridas.

Em sete casos não foi realizada a visitação, pois quatro deles eram relativos a agressões provocadas por animais silvestres e, nos outros três, eram desconhecidos o endereço e/ou telefone.

Dentre os dados registrados na ficha de visita zoossanitária durante as entrevistas do médico veterinário, um é com relação à espécie agressora. Sessenta e um acidentes foram provocados pela espécie canina e, três, pela felina. Desses animais, 78,1\% foram declarados domiciliados, 15,7\% peridomiciliados e $6,2 \%$ de vizinhança.

Outro dado refere-se à condição vacinal antirrábica do animal, em que a grande maioria dos animais foi declarada como não vacinada contra a raiva no último ano.

No presente estudo, a avaliação sanitária dos animais agressores foi realizada por médico veterinário em visita domiciliar. Durante a primeira visitação (dia zero), dos 64 animais agressores, 54 estavam sadios; cinco desapareceram; quatro morreram por motivos não relacionados à raiva (atropelamento, envenenamento, briga), e um foi sacrificado. $\mathrm{O}$ status sanitário dos 54 animais manteve-se normal durante dez dias de observação, sendo que no dia 5 o contato foi realizado por telefone e, no dia 10 , foi novamente realizada a visita.

A maioria $(43,7 \%)$ das agressões ocorreu por animais da própria vítima; $9,4 \%$ por animais de parentes; $18,8 \%$ por animais de vizinhos; $7,8 \%$ por animais de amigos; $9,4 \%$ por animais de proprietário sem relação nenhuma com a vítima; e 10,9\% por animais com dono desconhecido.

A conduta não sofreu interferência dos dados das fichas de visita zoossanitária, pois essas não foram apresentadas ao médico responsável.

Das 64 notificações registradas nas fichas de atendimento antirrábico humano, em 54 casos o animal estava sadio no momento da agressão e assim se manteve durante o período de dez dias; quatro morreram por outros motivos (atropelamento, envenenamento e briga); um animal foi sacrificado pelo proprietário; e apenas cinco desapareceram após a agressão.

Foram tratadas com pelo menos uma dose de vacina 57 vítimas, totalizando 161 doses.

Houve indicação de soro antirrábico em três casos: um deles se refere a vítima agredida por animal de rua desconhecido e que desapareceu em seguida; outro, a agressão pelo próprio cão que morreu após atropelamento; e uma terceira, também a vítima mordida pelo próprio cão durante uma brincadeira, e que sacrificou o animal logo em seguida.

Com relação ao fator desencadeante do ataque, 25 casos foram por motivos comportamentais normais dos animais frente a ameaças ou estresses evidentes, como defesa de território, medo, dor, ciúme do dono, defesa dos filhotes e do alimento; cinco casos foram provocados por instrumentos que condicionam o ataque, ou seja, moto ou bicicleta; 14 casos, por culpa da própria vítima, com agressão ao animal, brincadeiras, provocações, tratamento de feridas; 15 agressões ocorreram porque a vítima foi separar briga entre os animais, geralmente de sua propriedade; e cinco casos ocorreram sem motivo aparente.

A conduta profilática adotada no período do presente estudo variou de acordo com cada caso. Quando o histórico da agressão era o mesmo, o emprego do tratamento 
dependia da região anatômica alvo da mordedura; em caso de agressão em mão/pé, cabeça/pescoço, era indicada a vacinação antirrábica.

\section{Discussão}

Com relação ao número de agravos, notou-se diminuição na taxa de notificação de agressões, que era de 1:160 (FRIAS, LAGES, CARVALHO, 2011). Um dos fatores que pode ter contribuído para a diminuição da ocorrência de agravos é a atividade de educação em saúde sobre posse responsável de animais de estimação e controle de zoonoses, especialmente a raiva, que vem sendo desenvolvida no Município por um grupo de trabalho de extensão do Departamento de Medicina Veterinária Preventiva e Reprodução Animal da FCAV/Unesp.

Uma questão importante a salientar é que se sabe, por meio de questionários aplicados em entrevistas com a população de Jaboticabal, que um grande número de pessoas agredidas não procura atendimento médico (LAGES, 2009). Por isso, pode-se afirmar que a taxa real de acidentes no $\mathrm{Mu}$ nicípio é ainda maior.

Houve casos da pessoa envolvida no acidente já ter recebido profilaxia antirrábica anteriormente, e comparativamente, Garcia et al. (1999) citaram a ocorrência de tratamento anterior em $25,8 \%$ dos casos, e a não ocorrência em 71,4\%. Müller et al. (2010) constataram que 95,7\% das pessoas expostas não haviam recebido tratamento anterior. Já Rigo \& Honer (2005) observaram que 12,3\% das pessoas atendidas haviam recebido tratamento anterior e que $62,3 \%$ das fichas não tinham esse campo preenchido, assim como nesta pesquisa. Mesmo assim, notou-se que ocorreu uma diminuição significativa do não preenchimento de campos da ficha de atendimento antirrábico humano, quando se compara ao levantamento de 2000 a 2006, fato que certamente está relacionado com ações do serviço de vigilância em decorrência das recomendações geradas pelo trabalho de Frias (2008).

Durante os anos de estudo, o cão foi o responsável pela maioria dos acidentes, em todos os anos. Outras investigações também detectaram a espécie canina como a causadora da maioria dos agravos (BRANDÃO, 2010; MÜLLER, SEGER, GABIATTI, 2010; SILVA \& FREITAS, 2011; FILGUEIRA, CARDOSO, FERREIRA, 2011; PINTO et al., 2011).

Assim como neste estudo, vários autores relataram que na maioria dos agravos o animal foi declarado sadio e que mantiveram-se sadios durante o período de observação (GARCIA et al., 1999; RIGO \& HONER, 2005; MÜLLER, SEGER, GABIATTI, 2010 e FILGUEIRA, CARDOSO, FERREIRA, 2011).

No período estudado, a maioria das pessoas envolvidas em acidentes com animais foram submetidas ao tratamento com uso de vacina antirrábica. $\mathrm{O}$ número de casos conduzidos apenas com a observação do animal, ou seja, sem instituição de vacina, foi $25,7 \%$. Pode-se comparar este resultado com o índice encontrado por Pinto \& Alleoni (1986) e Filgueira et al. (2011), quando os últimos autores relataram somente observação do animal em 10,6\% dos casos. Segundo a pesquisa realizada por Carvalho et al. (2002), a conduta de apenas observar o animal foi adotada em 59,1\% dos casos; Garcia et al. (1999) citaram 50,6\%; Silva et al. (2011), 78\%, e Müller et al. (2010) relataram somente observação do animal em $91,5 \%$ dos casos atendidos.

O número de indicações de tratamento antirrábico pós-exposição em Jaboticabal é considerado alto $(74,3 \%$ das pessoas foram tratadas) quando comparado com os resultados de Pinto \& Alleoni (1986), Garcia et al. (1999), Carvalho et al. (2002), Ostrowska et al. (2003), Rigo \& Honer (2005) e Kilic et al. (2006). No Estado do Paraná, no ano de 1999, 22.897 pessoas procuraram médico devido a algum tipo de agravo e, destas, 54\% receberam tratamento antirrábico pós-exposição (PARANÁ, 2000). No Brasil, a porcentagem de tratamentos a pessoas agredidas foi de 62,4\% em 1999; 56,06\% em 2001 (ARAUJO, 2001).

Falhas na instituição da profilaxia pós-exposição em humanos, assim como nesta pesquisa, foram encontradas. Moran et al. (2000), em pesquisa realizada nos Estado Unidos, também detectaram falhas na indicação de tratamentos, onde $40 \%$ deles foram excessivos. Por outro lado, alguns autores citaram mais de $90 \%$ de sucesso na conduta de profilaxia antirrábica pós-exposição (CARVALHO, SOARES, FRANCESCHI, 2002; LANGE, LUHN, GABARDO, 2002).

Notou-se, também, que a indicação de tratamento pós-exposição também foi feita com base apenas na caracterização do agravo e não foi considerada a condição epidemiológica da doença no Município e nem a condição do animal no momento da agressão. Esses dados são muito importantes e isso foi demonstrado na pesquisa de Bentanzos Lopez et al. (2006) realizada em Chiapas no México, que analisaram 28 acidentes graves com mordedura de cães. Como os agredidos residiam em áreas de raiva controlada e a estrita vigilância do animal era realizada, não foi implantado nenhum tipo de tratamento antirrábico e ninguém desenvolveu a doença.

Erros de conduta foram descritos por Oliveira et al. (2006) em um estudo retrospectivo feito no Estado de Minas Gerais durante os anos de 1999 a 2004, quando se constatou a indicação excessiva de tratamentos pós-exposição em áreas de baixo e médio risco para a doença, e poucas indicações em áreas de alto risco.

Algumas informações são fundamentais para o estudo epidemiológico e avaliação dos acidentes com animais, dentre elas: a procedência do animal, sua condição de saúde, o tipo de relação com a vítima, o local geográfico e a circunstância em que ocorreu a agressão. Mesmo sendo essenciais, essas informações não constam da ficha de atendimento antirrábico humano do SINAN. Alguns autores também relataram esse problema em suas pesquisas (FORTES et al., 2007; BUSO, NUNES, QUEIROZ, 2009). Por este motivo, foi acrescentado um anexo na ficha em que está vigorando atualmente contendo estes campos essenciais.

Com a utilização do anexo da ficha de atendimento antirrábico humano, notou-se que $47,9 \%$ das vítimas declararam animal vacinado contra a raiva. Neste caso, esta questão deve ser analisada com muito critério, pois no ano de 2010 houve interrupção da campanha de vacinação antirrábica no Município de Jaboticabal, onde apenas $10 \%$ da população de cães e gatos de um distrito desse Município foram vacinados em Campanha. Além disso, quando questionadas sobre a situação vacinal do animal agressor, é possível que as vítimas (ou responsáveis) tenham respondido a esta questão sem ter certeza se o animal havia sido vacinado, ou consideraram a vacinação em algum momento da vida do animal. De fato, na 
ficha a questão deveria estabelecer "animal vacinado contra a raiva nos últimos 12 meses". Além disso, é necessário que os atendentes estejam mais preparados e conscientes da importância desse dado, para insistir na questão, quando for o caso.

Com relação à circunstância do ataque, o provocado foi o de maior ocorrência. Outros autores relataram este fato, e frisaram a ocorrência de ataques provocados principalmente quando a vítima era criança (FORTES et al., 2007). Quanto à localização geográfica onde ocorreu a agressão, a residência foi declarada o maior número de vezes corroborando com os resultados de outros estudos (BUSO; NUNES; QUEIROZ, 2009; BRANDÃO, 2010). Cumpre lembrar que esse dado é muito importante, pois além de contribuir para a avaliação epidemiológica do caso, ainda pode auxiliar os gestores de unidades de controle de zoonoses na tomada de decisão quanto ao controle de populações canina e felina, principalmente quando as agressões acontecem em via pública, fato este característico quando é elevado o número de animais errantes (FILGUEIRA; CARDOSO; FERREIRA, 2011).

No que se refere à conduta médica adotada, o mais comum foi a indicação de aplicação de vacina antirrábica associada a observação do animal, considerando apenas a região anatômica atingida e gravidade das lesões.

De acordo com as Normas Técnicas de Profilaxia Antirrábica Humana, além da região anatômica atingida e gravidade das lesões, outros fatores devem ser considerados, entre eles, a espécie animal, o estado de saúde do agressor no momento do acidente, a possibilidade de ser observado, a condição sanitária e os hábitos de vida do animal, e a epidemiologia da raiva no município (BRASIL, 2000; BRASIL, 2014).

Dessa forma, pode-se deduzir que maiores cuidados e melhores critérios deveriam ser usados para não ser instituído o tratamento de forma inadequada. Para isso, uma atuação mais incisiva do serviço de vigilância em saúde deveria ser imposta no que se refere à avaliação de cães e gatos agressores; à comunicação, a tempo, dos resultados dessa avaliação; e à colheita e remessa de amostra do Sistema Nervoso Central dos animais agressores que morrem. A expectativa é oferecer aos médicos dos serviços de profilaxia antirrábica humana a segurança necessária para dispensar ou indicar a aplicação de vacinas. Percebeu-se que, no município em estudo, esses pontos não foram considerados. Jaboticabal pode ser classificado como área de raiva controlada, sem casos da doença há mais de 40 anos em humanos e desde 1982 em cães e gatos, segundo os dados da Vigilância Epidemiológica. Além disso, a maioria dos ataques foram provocados e ocorreram na residência, consequentemente por animais passíveis de observação.

Uma questão importante a salientar é a falta de preenchimento de campos do anexo da ficha. Essa informação deixou clara a necessidade de maior conscientização da importância do preenchimento correto das fichas de registro e de capacitação e atualizações permanentes das equipes de saúde, para que a Vigilância Epidemiológica cumpra corretamente seu papel. A supervisão contínua poderia ser fator de resolução de falhas e dificuldades na aplicação das fichas de atendimento antirrábico humano (CARVALHO; SOARES; FRANCESCHI, 2002). Como já discutido neste trabalho, informações corretas são subsídios importantes para uma con- duta adequada frente a casos de agressão por animais.

Os acidentes provocados por animais ainda acontecem com frequência elevada, mas os próprios profissionais da saúde reconhecem que os casos notificados de agressão canina representam uma pequena parte do problema, pois geralmente são notificadas apenas agressões que resultam em uma lesão séria, de acordo com a avaliação que a própria pessoa agredida faz. Assim, as informações sobre as agressões são imprecisas, os dados obtidos são escassos e não mostram a verdadeira dimensão do problema, assim como também referiu Prada (2005).

Os registros dos serviços de assistência médica reúnem apenas dados seculares de lesões provocadas por animais, em pessoas que acham que estão em situações de risco; por isso, alguns autores relacionam a subnotificação dos acidentes com o nível de educação da vítima, a gravidade da lesão, a atitude de notificar, entre outras razões (PRADA, 2005). Neste contexto, a ficha referência de agressão animal torna-se importante instrumento, já que contempla campos de informação os quais, corretamente preenchidos, demonstram a real circunstância da agressão, pode orientar a conduta na aplicação de ações efetivas voltadas ao agressor e à vítima, e o acompanhamento do caso pelo Serviço de Vigilância Epidemiológica; ademais, permite rastrear os casos subnotificados, uma vez que possui o campo de endereço e telefone da vítima, possibilitando o contacto e a conscientização sobre a importância e a necessidade de dar prosseguimento ao tratamento indicado.

No período do plano piloto, por meio da aplicação da ficha referência de agressão animal, foram detectadas algumas subnotificações. Dentre estas vítimas, algumas já receberam a primeira dose de vacina antirrábica no momento do atendimento, porém, nenhuma delas precisaria ter recebido a vacina imediatamente, se o médico responsável tivesse avaliado os dados de investigação epidemiológica contidos na ficha referência de agressão animal. Essas pessoas deveriam apenas ter sido encaminhadas ao CIAF6 para avaliação mais precisa do caso; a observação do animal agressor daria mais segurança para a correta conduta na instituição do tratamento antirrábico pós-exposição. Além disso, a taxa de subnotificação de agressão animal no Município é significativo pois, no período de estudo completo (2007 a 2010), incluindo esses 90 dias, a média anual de agressões por animais notificadas foi de 342 ; considerando $21 \%$ de subnotificação, esse número pode chegar a 394 agressões anuais. Portanto, pode-se afirmar que o número real de agressões por animais no Município de Jaboticabal está subestimada.

Em alguns casos de subnotificações, não foi possível realizar a visitação, pois eram desconhecidos o endereço e/ou telefone. As informações sobre a possibilidade de contato com a vítima são essenciais e sua falta também foi referida em outros trabalhos (VELOSO et al., 2011).

Assim como neste trabalho, Brandão (2010) relatou, no estudo realizado em Corumbá/MS, que a maioria das agressões ocorreu também por instinto de defesa do animal, sendo provocados pela própria vítima. Reichmann (2007) discute sobre o comportamento dos animais agressores e também afirma que raramente os animais mordem sem uma provocação, e que nem sempre essa reação do animal é interpretada pelo ser humano como uma reação natural. Muitos agravos são resultantes de sensações dolorosas impostas a 
animais doentes ou por maus tratos, outros são causados por descuido, como pisadas e puxão de pelos. De fato, pouco as pessoas sabem de comportamento animal, e esse tema deve ser incluído nos trabalhos de educação para posse responsável de animais de estimação.

No Estado de São Paulo, a análise dos casos de mordedura demonstra que $80 \%$ ou mais de agravos são causados por cães de proprietários ou cães de família, envolvendo pessoas da própria família, parentes ou vizinhos (BRASIL, 2003). Buso et al (2009) e Brandão (2010) também relataram em suas pesquisas que a maioria dos animais agressores eram domiciliados, assim como nesta pesquisa.

Os dados da ficha de visita zoossanitária relacionados a condição vacinal do animal agressor são os corretos, quando comparados aos encontrados no anexo da ficha, assim como já discutido anteriormente, uma vez que não ocorreu a campanha de vacinação antirrábica em 2010. Isso demonstra a importância da visita ao animal agressor e a verificação da carteira de vacinação do mesmo. Analisando sob o ponto de vista do Ministério da Saúde e das autoridades sanitárias responsáveis pelo controle da raiva no Brasil, a condição de vacinação do animal agressor não deve ser um dado confiável, mesmo com certificado de vacinação, pois o animal pode estar vacinado, mas não imunizado; portanto, não seria uma informação relevante. Concorda-se, aqui, que isoladamente esse dado não seja relevante, mas quando analisado no conjunto das informações, com base nas visitas domiciliares e, especialmente, na condição epidemiológica da raiva no município e na região, torna-se essencial para auxiliar a conduta médica em casos de agressão.

Cumpre informar que, em estudos com aplicação de questionários casa a casa em Jaboticabal, realizados há quase dez anos por um grupo do Laboratório de Pesquisa em Raiva do Departamento de Medicina Veterinária Preventiva e Reprodução Animal da Faculdade de Ciências Agrárias e Veterinárias da Unesp - Câmpus de Jaboticabal/SP, os resultados registram declaração de vacinação antirrábica de animais de estimação sempre em torno de 80\% (NUNES, 2011).

Quanto à observação do animal agressor, esta deve ser supervisionada por médico veterinário ou agente do serviço municipal de vigilância da raiva em visita domiciliar ou canil público (BRASIL, 2000; BRASIL, 2014), assim como proposto neste estudo. O resultado da observação do animal agressor (cão ou gato) deve ser prontamente informado à vigilância epidemiológica para a tomada de providências necessárias (BRANDÃO, 2010). Com a avaliação clínica do animal observável é possível determinar a conduta profilática visando evitar a aplicação desnecessária de vacina antirrábica (FILGUEIRA; CARDOSO; FERREIRA, 2011).

Por meio da realização desta observação, detectamos que a maioria dos animais agressores, estavam sadios durante todo o período de observação. Rolim et al (2006), em um estudo realizado em Jacarezinho/PR, no mesmo esquema de três visitas, descreveram o estado clínico dos animais como sadio em $96,8 \%$ das observações.

A avaliação da indicação de vacina antirrábica não sofreu interferência dos dados das fichas de visita zoossanitária, pois estas não foram apresentadas ao médico responsável, uma vez que se pretendia ratificar a importância da observação animal para incluir essa ação na elaboração da proposta objetivo da presente pesquisa.
De acordo com a avaliação da conduta relacionada aos casos de agressão, neste trabalho, deveria ser predominantemente a observação do animal, amparada pelo conhecimento da situação epidemiológica da raiva no município e das características das agressões (todas provocadas pela vítima). Essas informações dão muita segurança para a conduta de apenas observar o animal agressor.

A Norma Técnica de Profilaxia Antirrábica Humana estabelece que, em municípios de baixo risco, seja priorizada a observação intensiva dos animais, ao invés do tratamento antirrábico das pessoas agredidas (BRASIL, 2014). Com isso, constatou-se que apenas as vítimas dos cinco animais que desapareceram deveriam ter recebido a vacina antirrábica, já que os demais puderam ser observados e houve possibilidade de diagnóstico laboratorial para os casos de morte. Vale ressaltar que não foi remetido material para análise laboratorial de raiva dos animais que morreram naturalmente nem do que foi sacrificado, procedimento importante e necessário para fechar um diagnóstico e dar suporte à conduta de atendimento de agredidos.

A recomendação de observar os animais agressores nem sempre é atendida devido a inexistência de condições para tal, a falta de instrumento adequado para registro dos dados e tomada de decisões (CARVALHO; SOARES; FRANCESCHI, 2002), além da supervalorização dos procedimentos de medicina assistencial em comparação com aqueles de medicina preventiva. Se a ficha de visita zoossanitária se tornar um documento oficial, com aplicação obrigatória, esses problemas serão reduzidos.

Nos casos de indicação de soro antirrábico, houve uma descrição precisa dos casos devido a aplicação da ficha de visita zoossanitária. Se esses dados estivessem em posse do médico responsável, e se tivesse sido enviado ao laboratório material dos animais que vieram a óbito, provavelmente as vítimas não seriam encaminhadas para sorovacinação.

\section{Conclusões}

A associação dos dados da ficha de visita zoossanitária e do novo modelo de ficha de atendimento antirrábico humano, especialmente aqueles relativos à descrição do acidente e observação do animal agressor, aliada a uma análise criteriosa da condição epidemiológica da doença, podem oferecer fortes subsídios para orientar a conduta médica e a decisão de se instituir ou não tratamento antirrábico pós-exposição. Ademais, médicos e médicos veterinários devem atuar de forma integrada para que a decisão para instituição ou não de tratamento antirrábico pós-exposição seja tomada com critério e segurança.

A estratégia proposta com a implantação das novas fichas mostrou-se viável e possibilitou a obtenção de informações mais precisas e fidedignas que poderão orientar a indicação de tratamento antirrábico humano pós-exposição. Por isso, tornar essas fichas documentos oficiais do Ministério da Saúde seria essencial para dar a segurança que os profissionais de saúde tanto necessitam.

Ficou evidente que os campos de preenchimento incluídos na ficha de atendimento antirrábico humano são necessários, e os dados neles contidos auxiliam na avaliação da agressão animal. Embora a ficha de atendimento antirrábico humano, instituída pelo Ministério da Saúde, tenha sido um 
marco na notificação de mordeduras e outros agravos, ficou claro que possui falhas e que estas precisam ser corrigidas para se atingir o nível ideal de segurança na indicação de tratamento antirrábico pós-exposição. Portanto, é importante que sejam incluídos, em seu formulário, as questões citadas na presente pesquisa, além da capacitação contínua e supervisão dos profissionais envolvidos em seu preenchimento.

A visita zoossanitária com aplicação da respectiva ficha possibilitou uma análise criteriosa das causas de agressão por animais e demonstrou que as pessoas têm dificuldade em entender o comportamento animal. Este tema deve ser incluído e discutido nos trabalhos de educação em saúde, visando à diminuição do número de agravos.

A observação de cães e gatos agressores e a avaliação do perfil epidemiológico da raiva no município são indispensáveis, uma vez que podem reduzir a prescrição desnecessária de vacina antirrábica humana e o desperdício de recursos.

É fundamental que os profissionais de saúde atuem de forma integrada e tenham condições de avaliar todos os aspectos envolvidos em cada caso para instituir o tratamento antirrábico pós-exposição com critério e segurança.

\section{Referências}

ARAÚJO, F. A. A. Situação epidemiológica da raiva: panorama brasileiro. In: SIMPÓSIO INTERNACIONAL PROGRAMA DE TREINAMENTO "CONTROLE DE ZOONOSES E AS INTERAÇÕES HOMEM-ANIMAL”, 2001, Embu. Anais... Embú: Arca Brasil, 2001. p. 29.

BELOTTO, A. et al. Overview of rabies in the Americas. Virus Research, v. 111, n.1, p. 5-12, 2005.

BENTANZOS LOPEZ, R. et al. Manejo de pacientes com lesiones graves provocadas por perro em áreas com ausência de casos de rabia canina, em el estado de Chiapas México. In: REUNIÃO INTERNACIONAL DE RAIVA NAS AMÉRICAS, 17.; 2006, Brasília. Anais... Brasília: Ministério da Saúde, 2006. p. 48.

BRASIL. Ministério da Saúde. Secretaria de Estado da Saúde. Instituto Pasteur. Manual de profilaxia da raiva humana. 2. ed. São Paulo: Instituto Pasteur, 2000. 44 p.

Secretaria de Estado da Saúde. Instituto

Pasteur. Situação epidemiológica e do Programa de controle da raiva no Estado de São Paulo. São Paulo: Instituto Pasteur, 2003. (Relatório de atividades).

Secretaria de Vigilância em Saúde.

Normas técnicas de profilaxia da raiva humana.

Disponível em: <http://portal.saude.gov.br/portal/arquivos/ pdf/normas_tec_profilaxia_da_raiva_hum.pdf. $>$. Acesso em: 18 nov. 2014.

BRANDÃO, G. C. Epizootia da raiva canina no Município de Corumbá em 2008: descrição e avaliação dos atendimentos antirrábicos humanos. 2010. $52 \mathrm{f}$. Dissertação (Mestrado em Saúde Pública) - Escola Nacional de Saúde Pública Sérgio Arouca, Rio de Janeiro, 2010.
BUSO, D. S.; NUNES, C. M.; QUEIROZ, L. H. Características relatadas sobre animais agressores submetidos ao diagnóstico de raiva, São Paulo, Brasil, 1993-2007. Cadernos de Saúde Pública, v. 25, n.12, p. 2747-2751, 2009.

CARVALHO, W. O; SOARES, D. F. P. P.; FRANCESCHI, V. C. S. Características do atendimento prestado pelo serviço de profilaxia da raiva humana na rede municipal de saúde de Maringá-Paraná, no ano de 1997. Informe Epidemiológico do SUS, v.11, n.1, p. 25-35, 2002.

FILGUEIRA, A. C.; CARDOSO, M. D.; FERREIRA, L. O. C. Profilaxia antirrábica humana: uma análise exploratória dos atendimentos ocorridos em Salgueiro-PE, no ano de 2007. Epidemiologia e Serviços de Saúde, v. 20, n.1, p. 233-244, 2011.

FORTES, F. S. et al. Acidentes por mordeduras de cães e gatos no Município de Pinhais, Brasil de 2002 a 2005. Archives of Medicine Veterinary Science, v.12, n. 2, p.1624, 2007.

FRIAS, D. F. R. Avaliação dos registros de profilaxia antirrábica humana pós-exposição no Município de Jaboticabal, São Paulo, no período de 2000 a 2006. 2008. 66 f. Dissertação (Mestrado em Medicina Veterinária) Universidade Estadual Paulista - UNESP, Jaboticabal, 2008.

FRIAS, D. F. R.; LAGES, S. L. S.; CARVALHO, A. A. B. Avaliação da conduta de profilaxia antirrábica humana indicada para pessoas envolvidas $\mathrm{m}$ agravos com cães e gatos no Município de Jaboticabal, SP, no período de 2000 a 2006. Revista Brasileira de Epidemiologia, v. 14, n. 4, p. 722-732, 2011.

GARCIA, R. C. M. et al. Análise de tratamento anti-rábico humano pós-exposição em região da Grande São Paulo, Brasil. Revista de Saúde Pública, v. 33, n. 3, p. 295-301, 1999.

IBGE. INSTITUTO BRASILEIRO DE GEOGRAFIA E ESTATÍSTICA. Estimativas de projeções populacionais. Disponível em: <ftp://ftp.ibge.gov.br/Estimativas Projecoes_Populacao $>$. Acesso em: 08 ago. 2011.

KILIC, B. et al. An important public health problem: rabies suspected bites and pos-exposure prophylaxis in a health district in Turkey. International Journal of Infectious Diseases, v. 10, n. 3, p. 248-254, 2006.

LAGES, S. L. S. Avaliação da população de cães e gatos com proprietário, e do nível de conhecimento sobre a raiva e posse responsável em duas áreas contrastantes da cidade de Jaboticabal, São Paulo. 2009. 76 f. Dissertação (Mestrado em Medicina Veterinária) - Faculdade de Ciências Agrárias e Veterinária, Departamento de Medicina Veterinária Preventiva e Reprodução Animal, Universidade Estadual Paulista - UNESP, Jaboticabal, São Paulo, 2009. 
LANGE, M. F. L.; LUHN, K. R.; GABARDO, B. M. A. Avaliação do atendimento antirrábico humano em Curitiba. In: CONGRESSO BRASILEIRO DE EPIDEMIOLOGIA, 5., 2002, Rio de Janeiro. Anais... Rio de Janeiro:

ABRASCO, 2002. p. 266.

MORAN, G. J. et al. Appropriateness of rabies postexposure prophylaxis treatment for animal exposures. Emergency ID net study group. Journal of the American Medical Association, Chicago, v. 284, n. 8, p. 1001-1007, 2000 .

MÜLLER, G. C.; SEGER, J.; GABIATTI, L. L. Avaliação dos casos de atendimento antirrábico humano notificados no Município de São Miguel do Oeste - SC no ano de 2009. Unoesc \& Ciência - ACBS, v. 1, n. 2, p. 95-105, 2010.

NUNES, J. O. R. Contribuição para o estudo da dinâmica de populações de cães e gatos do Município de Jaboticabal, São Paulo. 2011. 91 f. Dissertação (Mestrado em Medicina Veterinária) - Universidade Estadual Paulista - UNESP, Jaboticabal, 2011.

OLIVEIRA, V. M. R. et al. Evaluation of the human antirabic service, Minas Gerais, Brazil, 1999 to 2004. In: REUNIÃO INTERNACIONAL DE RAIVA NAS AMÉRICAS, 17., 2006, Brasília. Anais... Brasília: Ministério da Saúde, 2006. p.164.

OLIVEIRA, A.V. B.; SILVA, R. A.; GOMES, A. A. B. A campanha nacional de vacinação contra a raiva animal nos Municípios da Microrregião de Catolé da Rocha - PB no período de 2006 a 2007. Revista Verde de Agroecologia e Desenvolvimento Sustentável, v. 5, n.1, p. 101-119, 2010.

OSTROWSKA, J. D. et al. Evaluation of the prophylactic anti-rabies vaccination program for adults carried out by the Center for Rabies Prevention in Bialystok, 1992-2001. Medycyna Pracy, Polônia, v. 54, n. 5, p. 453- 456, 2003.

PARANÁ. Secretaria da Saúde do Estado do Paraná. Boletim Epidemiológico, a. 3, n. 11, 2000. Disponível em: <http://www.saude.pr.gov.br/vigiepi/boletim/ primavera_2000/raiva_humana.htm>. Acesso em: 15 jul. 2011.

PINTO, C. L.; ALLEONI, E. S. Aspectos da vigilância epidemiológica da raiva em sub-regiões administrativas do Estado de São Paulo, Brasil, 1982-1983. Revista de Saúde Pública, São Paulo, v. 20, n. 4, p. 288-292, 1986.

PINTO, H. B. F. et al. Avaliação do custo-benefício das atividades de prevenção da raiva humana e das atividades de controle da raiva canina no Município de Mogi Guaçu, Estado de São Paulo, período de 2000 a 2004 . Veterinária e Zootecnia, v. 18, n. 1, p. 122-122, 2011.

PRADA, B. M. A. Estudo de caso de agressões por cães no município de Araraquara, São Paulo, Brasil. 2005. 51 f. Monografia (Especialização em Saúde Pública) Universidade Estadual Paulista Júlio de Mesquita Filho -
UNESP, Araraquara, 2005.

REICHMANN, M. L. A. B. Impacto de medidas de prevenção de agravos produzidos por animais da espécie canina, em carteiros da empresa de correios e telégrafos do Estado de São Paulo, no período de 2000 a 2004. 2007. 133 f. Tese (Doutorado em Epidemiologia Experimental e Aplicada as Zoonoses) - Universidade de São Paulo, São Paulo, 2007.

RIGO, L.; HONER, M. R. Análise da profilaxia da raiva humana em Campo Grande, MS, Brasil em 2002. Cadernos de Saúde Pública, v. 21, n. 6, p. 1939-1945, 2005.

ROLIM, R. L. P.; LOPES, F. M. R.; NAVARRO, I. T. Aspectos da vigilância epidemiológica da raiva no Município de Jacarezinho, Paraná, Brasil, 2003. Semina: Ciências Agrárias, v. 27, n. 2, p. 271-280, 2006.

SCHNEIDER, M. C. et al. Current status of human rabies transmitted by dogs in Latin America. Cadernos de Saúde Pública, v. 23, p. 2049-2063, 2007.

SILVA, A. M. R.; FREITAS, S. F. T. Características do atendimento antirrábico humano no Estado de Santa Catarina, área considerada sob controle para a raiva no ciclo urbano - 2002 a 2007. 2011. Disponível em: $<$ http://www.dive.sc.gov.br/conteudos/publicacoes/tcc/ Caracteristicas_do_atendimento_anti-rabico_humano_no_ sc.pdf>. Acesso em: 24 set. 2011.

VELOSO, R. D. et al. Motivos de abandono do tratamento antirrábico humano pós-exposição em Porto Alegre (RS, Brasil). Ciência \& Saúde Coletiva, v.16, n. 2, p. 537-546, 2011.

Recebido: 30/03/2015

Aceito: 01/02/2016 